\title{
Procedimientos de creación léxica en las designaciones iberorrománicas del párpado (II) ${ }^{*}$
}

\author{
Carolina JULIÀ LUNA \\ Departamento de Filología Española \\ Universitat Autònoma de Barcelona \\ carolina.julia@uab.cat
}

\section{RESUMEN}

El objetivo de la presente investigación ${ }^{1}$ es el estudio de las denominaciones del párpado en las lenguas iberorrománicas a partir del examen de los datos que contienen los atlas lingüísticos del español, el catalán, el gallego y el portugués. Los resultados obtenidos permiten dar cuenta del valor de los materiales sobre el léxico iberorrománico que contienen los atlas lingüísticos para dar cuenta de que la metáfora y la metonimia son los dos mecanismos semánticos más frecuentes en los procesos de creación del léxico popular.

Palabras clave: metáfora, metonimia, geografía lingüística, lenguas iberorrománicas

[Recibido, septiembre 2010; aprobado, diciembre 2010]

\author{
Some procedures of lexical creation \\ in the Ibero-Romance names of the 'eyelid'
}

\begin{abstract}
The goal of this research is to study the names of the 'eyelid' in the Ibero-Romance languages, after having examined the data contained in the linguistic atlases of Spanish, Catalan, Galician and Portuguese.The results allow us to say how valuable the linguistic atlases are in order to consider metaphor and metonymy as the two most frequent procedures of popular lexical creation.
\end{abstract}

Keywords: metaphor, metonymy, linguistic geography, Ibero-Romance languages

\footnotetext{
* El presente artículo es la segunda parte del publicado en el volumen 28 (2011) de esta Revista.

${ }^{1}$ El desarrollo de esta investigación ha sido posible gracias a la ayuda de la DGICYT (n. ${ }^{\circ}$ de ref. FFI2008-06324-C02-01) y del Comissionat per Universitats i Recerca de la Generalitat de Catalunya (n. ${ }^{\circ}$ de ref. SGR2009-1067).
} 


\section{Análisis de las denominaciones procedentes de palpĕbra y palpětra, -um}

Antes de iniciar el análisis de las formas de origen metafórico y metonímico (§ 4), se ha considerado oportuno destinar un apartado al estudio etimológico y semántico de las formas latinas PALPĔBRA y PALPĚTRA, -UM no solo porque son las que dan lugar a las denominaciones más extendidas de las variedades iberorrománicas sino porque su origen semántico posee interesantes características desde el punto de vista de la creación del significado en relación con el resto de designaciones metafóricas y metonímicas.

Las formas del esp. párpado, el cat. parpella y el gall. y port. pálpebra son los únicos casos del corpus que no presentan una motivación transparente debido a que la evolución diacrónica de la lengua ha convencionalizado su uso (Dalbera 2006: 23). Actualmente, los hablantes no son conscientes del motivo que originó estas designaciones heredadas del latín — como sucede en buena parte del léxico patrimonial - a diferencia de lo que puede ocurrir en las formas de significado más o menos nítido que se analizarán en los próximos apartados (esp. cubierta del ojo, casa del ojo). Para ellos, la voz se emplea con el significado de 'párpado' por pura convención y, en consecuencia, se percibe como una palabra desmotivada. El análisis motivacional resulta imprescindible para poder determinar el origen semántico de los étimos latinos de los nombres iberorrománicos más frecuentes del párpado, para establecer el proceso semántico a partir del que se generó y también para comprobar la existencia de relaciones con las denominaciones metafórico-metonímicas halladas en los atlas lingüísticos.

\subsection{Origen de las voces latinas PALPĔBRA y PALPĔTRA, -UM}

Etimológicamente, la forma PALPĔBRA parece estar relacionada con la raíz indoeuropea *pōl- > *pal 'tocar, sentir o sacudir' (DEILE s. v. *pōl-). De este radical derivaron algunas palabras en diferentes lenguas de origen indoeu-

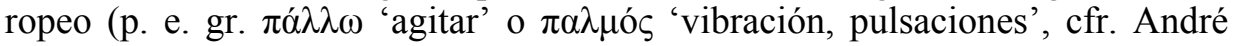
1991: 45) que poseen un evidente vínculo semántico con las formas latinas asociadas a este radical (palpor, -äris; palpare; palpitare; palpěbra, etc.)

Las voces del latín que llegaron desde el indoeuropeo con esta raíz, a diferencia de las del griego mencionadas anteriormente, sufrieron un proceso de reduplicación de la consonante bilabial originado, muy probablemente, por el significado de la raíz (André 1978). El movimiento repetido al que aludía *pōl$>$ *pal 'tocar, sentir o sacudir' generó la duplicación de la consonante oclusiva inicial y pasó a *pal-p-, forma a partir de la que André (1978: 37; 1991: 45) supone que surge *PALPERE 'estar animado por movimientos repetidos', étimo del que derivan, entre otras palabras latinas, PALPARE 'palpar, tocar con la mano, tentar', PALPOR, -ĀRIS 'tocar con la mano, dar golpecitos, acariciar', PALPITARE 'agitarse, latir' y PALPĚBRA 'párpados'. Así pues, el radical *pal-p- que comparten todas estas voces surge a partir de un proceso fonosimbólico (Ullmann 1980[1962]: 104; Malkiel 1990, 1994; Díaz Rojo 2002; Contini 2005; Carpitelli 2006; Poch 2010) ya que la duplicación de la consonante parece que 
surge con el fin de transmitir la idea de movimiento repetido al que se refiere la raíz. André (1978: 37) atribuye el origen de PALPĚBRA a la impresión que los hablantes tienen del movimiento de vaivén de esta parte del cuerpo y, además, cree que esta motivación explicaría que, en latín, PALPĚBRA se empleara únicamente como designación del 'párpado superior', «en tant qu'organe mobile» y que la denominación del 'párpado inferior' fuera GENA, -AE (vid. § 3.2.).

Para desentrañar el origen de PALPĚBRA deben analizarse sus características morfológicas y semánticas. Desde el punto de vista morfológico, dos son los elementos que constituyen la voz, el radical de origen indoeuropeo *palp- y el sufijo -bra (o -tra, -trum). Semánticamente, se puede añadir que la voz se ha formado a partir de esta raíz motivada por los movimientos repetidos que realiza el párpado. La raíz palp- denotaría, por lo tanto, la acción repetitiva y se uniría al sufijo femenino -bra que, según el DELL (s. v. PALPĚBRAE, ĀRUM), era un elemento morfológico habitual con el que se formaban nombres latinos de instrumentos (TEREBRA 'instrument à forer, à percer, driell, tarière, trepan, etc.') y otras voces (VERTĚBRA 'os du bassin').

La procedencia de las principales formas vulgares de PALPĚBRA (PALPĚTRA, PALPĔTRUM y PALFĚBRA) se relaciona con diversos aspectos histórico-lingüísticos (cuestiones fonético-fonológicas, de influencia de una lengua sobre otra y de morfología nominal). Tanto PALPĚTRA, -UM como PALFĚBRA, surgen por la acumulación de las tres consonantes labiales en PALPĚBRA (DECH s. v. párpado; André 1991; DHLF s. v. paupière) que motivaron diferentes procesos de disimilación. Asimismo, junto a los cambios disimilatorios, las variantes deben atribuirse a que, a partir de finales del siglo IV d. C., se produjo un cambio de género en el sustantivo (de femenino a neutro) debido a la influencia que ejerció la voz griega $\beta \lambda \varepsilon ́ \varphi \alpha \rho o v$ 'párpado', de género neutro, procedente de las traducciones latinas de algunos textos médicos griegos. De este modo, junto a la voz PALPĚBRA (femenino), se empezaron a dar casos de PALPĚBRUM (neutro). Además, el cambio de género favoreció el mantenimiento de una de las dos formas vulgares, PALPĚTRUM ya que, según el DELL (s. v. PALPĚBRAE, ĀRUM), eran mucho más frecuentes en latín las voces que terminaban con la forma -trum (PALPĚTRUM) que las que terminaban con -tra (PALPĚTRA), de modo que el cambio de género influido por las traducciones griegas fue respaldado por otros motivos de tipo léxico y morfológico.

\subsection{Significados de las voces latinas PALPĚBRA y PALPĚTRA, -UM}

El léxico de las partes del cuerpo humano se caracteriza, entre otros aspectos, por poseer un elevado grado de polisemia debido a que forma parte de un campo nocional de vital importancia en la categorización del mundo (Márquez Linares 1998). Los diferentes significados de los nombres que designan partes del cuerpo se corresponden con realidades ajenas a la anatomía y surgen por un proceso metafórico o atañen a otras partes del cuerpo y proceden de una metonimia. En el caso del léxico latino, el estudio de André (1991) evidencia el nada desdeñable número de significados metonímicos que los nombres de partes del 
cuerpo poseían. El análisis de las acepciones latinas de PALPĚBRA (y sus variantes) es una buena muestra de ello.

A pesar de que diversos textos latinos informan de que su significado más extendido fue 'párpado superior', PALPĚBRA también se empleó ocasionalmente, según André (1991), con el significado de 'pestañas'. Sin embargo, ciertos datos permiten demostrar que quizá no fue un uso tan extraño. Por un lado, existen algunos testimonios del romance medieval en los que el latín palpebra se hace corresponder con el romance pestañas (h. 1400, Glosario del Escorial ${ }^{2}$; Nebrija, 1973[1516]: Vocabulario de romance en latín). Asimismo, a partir de los datos del $R E W(6176 \mathrm{~s}$. v. palpěbra), se advierte que, en ciertas variedades románicas, una de las variantes vulgares de PALPĚBRA (> PALFĔBRA) ha dado lugar a formas que se emplean para designar las pestañas (gall. perfeba, ligur pibiristas) ${ }^{3}$. Además, según la remisión del $D E C H$ (s. v. párpado) a Sarmiento, el gallego perfeba también se empleó para designar la 'ceja', a lo que se debe añadir que el $A L G a$ ha recogido la variante perceba como denominación del 'párpado' (vid. § 2.2.). Asimismo, la voz PALPĚBRA parece que convivió con otras formas que también designaban el párpado: GENA, -AE ('párpado inferior' y 'mejilla') y CǏLIIUM ('párpado', 'pestaña', 'ceja'). Igualmente, André (1991:46) indica que algunos gramáticos latinos realizaron distinciones de significado en el uso de las formas clásicas y vulgares al emplear la voz del lat. clás. PALPĚBRA para designar las pestañas y las formas vulgares PALPĚTRA, UM para denominar el párpado.

Según los datos del $D E C H$ (s. v. ceja, pestaña, párpado) y los obtenidos en Julià (2007), se puede confirmar que, en latín, era muy habitual el intercambio denominativo entre las distintas partes del ojo y, en consecuencia, la polisemia del léxico referido a ellas. El origen del valor polisémico de estas partes es la metonimia causada, a su vez, por la proximidad entre las distintas partes del ojo y, probablemente, por la falta de distinción de rasgos diferenciales entre ellas (Labov 1994). Estos resultados, por ejemplo, se obtienen también en el mapa del concepto 'cogote' del ALeCMan (mapa 288), pues además de cogote recoge denominaciones que se corresponden con otras partes posteriores de la cabeza (coronilla, cuello, nuca, pescuezo) ${ }^{4}$.

\footnotetext{
${ }^{2}$ Este dato se ha extraído de la entrada párpado del $D E C H$, concretamente, del fragmento en el que se advierte que el «vulgo a veces no distingue bien [esta voz] de pestaña (que es voz más popular)».

3 Ambas formas se atestiguan, al menos una vez, en el mapa referido al concepto 'pestaña' de alguno de los atlas iberorrománicos estudiados. El gallego perfeba, que es la forma que registra el $D R A G$ (s. v. perfeba), aparece representado en el $A L G a$ (mapa 13, vol. V) por dos variantes formales, perceba (C 26 - Vilasantar y C 31 - Oroso) y profebra (C42 - Teo). Asimismo, la forma pibiristas, aunque no es propia de las variedades iberorrománicas, aparece en el punto de encuesta que el $A L D C$ (mapa 16, vol. I) sitúa en la isla de Cerdeña (85 - Alguer).

${ }_{4}^{4}$ El mapa incluye, además, una nota en la que se indica que los hablantes confunden también la posición en la que se encuentra el cogote: «Dicen que el cogote está más arriba de la nuca [...], debajo de la nuca $[\ldots]$, en la coronilla $[\ldots]$, en la parte de atrás [...], debajo de la coronilla [...], en la parte de atrás $[\ldots]$, debajo de la coronilla $[\ldots]$, en la parte de delante de la garganta $[\ldots]$ o en la parte baja del cuello, por delante» (ALeCMan, mapa 288).
} 


\subsection{Formas iberorrománicas descendientes del latín PALPĚBRA y PALPĚTRA,-UM}

El latín clásico PALPĚBRA, -AE 'párpado superior' y sus variantes vulgares (PALPĚTRA, -UM $)^{5}$ constituyen el origen de la denominación estándar del párpado en casi todas las lenguas románicas: el fr. paupière, el cat. parpella y el rum. pleoapă descienden de PALPĔTRA; el gall. pálpebra y el it. y port. palpebra de PALPĔBRA; y el esp. párpado de PALPĚTRUM.

PALPĚTRA, la variante vulgar femenina es la que ha originado, según el $R E W$ (s. v. 6176 palpěbra), un número mayor de formas léxicas en las distintas variedades lingüísticas de la Romania tanto para designar el párpado ${ }^{6}$ como otras realidades afines semánticamente (las pestañas, las legañas, la acción de dormir) que han surgido probablemente por un proceso metonímico.

PALPĚBRA, en cambio, parece que ha sido menos productiva, pues el $R E W$ sólo recoge descendientes de dos variedades románicas («it. palpebra, parm. parpebli»). Entre las formas que reúne, no se hallan ni el portugués ni el gallego pálpebra quizá porque son cultismos modernos ( $D E C H \mathrm{~s}$. v. párpado). El escaso número de ocurrencias en los atlas de la forma pálpebra tanto en Galicia como en Portugal es más que probable que sea consecuencia del carácter culto de la voz. El caso más representativo es el del gallego puesto que el $A L G a$ sólo recoge un ejemplo de esta forma frente a un número nada desdeñable de casos de la variante mayoritaria, que es el español párpado (vid. mapa 1), un uso que Negro Romero (2009: 243) califica de castellanismo en gallego. Además, entre los textos del TILG (Tesouro informatizado da lingua galega), la documentación pálpebra no se recoge hasta finales del siglo XIX (Aurelio Ribalta, 1894, Ferruxe, p. 24), por lo que se amplían las razones que explican la ausencia de la voz en el $A L G a$. En portugués, en cambio, aunque el cultismo es mucho más frecuente (35 registros en el $A L E P G$ ), cabe destacar que su presencia compite con la que es la forma antigua portuguesa para designar el párpado (capela o capela do olho, DECH s. v. párpado) y que se halla en 33 ocasiones en el mapa.

PALPĚTRUM es la forma latina que menos formas ha proporcionado a las variedades románicas, el esp. párpado es la única voz del corpus que deriva de ella.

\footnotetext{
${ }^{5}$ Cabe mencionar que, además de estas formas vulgares, PALPĚBRA, -AE posee también la variante PALFĚBRA que ha dado lugar a denominaciones relativas a otras partes del ojo (cfr. § 3.2. y § 4.2.). Acerca de la evolución fonético-fonológica de las variantes vulgares de esta voz latina, véase el DECH (s. v. párpado).

${ }^{6}$ Las numerosas formas que recoge el $R E W$ (s. v. 6176 palpěbra) pertenecen a más de una treintena de variedades románicas: «neap. parpétule, sillan. palpedna, bologn. palpeidra, crem. ferr., romagn. palpedra, venez. palpiera, lomb. palpera, piem. parpera, obw. palpeder, frz. paupière $(>$ südfrz. pauipieiro, kat. paupera) [...] pav., gen., piac. parpela, prov. palpela, parpela, kat. parpella, friaul. papele; prov. palperla, langued. pauperlo, lard. perpeure [...] piem. parpeila, wald. perpelo, béarn. perpet, Tarn: parpel, valenc. parpell; arbed. palpedig)».

${ }^{7}$ Es importante señalar que esta herramienta informática «recoge textos de todo género y registro desde 1612 a la actualidad» (Álvarez Pérez 2009: 120), por tanto, la primera documentación de las 268 ocurrencias que se obtienen en la consulta de este corpus es bastante tardía en relación a la fecha de los primeros textos que este incluye.
} 


\section{Análisis de las denominaciones de origen metafórico-metonímico}

Las denominaciones del párpado que proceden de algún proceso semántico de tipo metafórico o metonímico son las más numerosas, pues los atlas recogen casi medio centenar (49 formas) de designaciones de este tipo. Asimismo, son también las que resultan más interesantes desde el punto de vista de análisis semántico porque permiten advertir cuáles son las estrategias que subyacen en la mente de los hablantes de distintas variedades lingüísticas a la hora de conceptualizar y denominar una misma realidad cotidiana y común. Por este motivo, en el presente apartado, se estudian detenidamente las características del origen semántico de todas las designaciones de este grupo para determinar de qué modo se concibe mentalmente el párpado. Para ello, se han clasificado las denominaciones en función del tipo de metáfora o metonimia con el que se corresponden según la tipología de metáforas cognitivas que establecieron Lakoff y Johnson (1986[1980]).

\subsection{Variantes léxicas de origen metafórico}

En este grupo designativo, se distinguen las formas que surgen de metáforas conceptuales de las que proceden de metáforas de imagen y entre las primeras se establecen tres grupos en función de si son ontológicas, orientacionales o estructurales.

\subsubsection{Metáforas conceptuales}

\subsubsection{Metáforas ontológicas: la metáfora de recipiente}

El conjunto de denominaciones metafóricas más frecuente procede de una metáfora conceptual ontológica de recipiente. Las metáforas ontológicas se caracterizan por ser aquellas que permiten al ser humano considerar las entidades no discretas (actividades, emociones, ideas, pensamientos) como objetos o sustancias (Lakoff y Johnson 1986[1980]: 63). Aunque todas las metáforas, según la teoría experiencialista, poseen una fuerte vinculación con el cuerpo debido a que se originan gracias a la experiencia corpórea con el entorno (Cuenca y Hilferty 1999: 15-16), las metáforas ontológicas están estrechamente relacionadas con el cuerpo humano porque son nuestras experiencias corporales con los objetos físicos las que proporcionan la base para su creación. Este tipo de metáforas suele dividirse, además, en subtipos, entre los cuales, los más frecuentes son la metáfora de personificación, en la que un objeto no animado se concibe en términos de persona, y la metáfora de recipiente, en la que cualquier entidad se conceptualiza como un recipiente.

Así pues, la realidad que percibimos se halla fuera de nuestro cuerpo, y este se concibe, por ello, como un recipiente. Un ejemplo de metáfora de este tipo es el de considerar la mente humana como una entidad en la que se pueden introducir cosas: LA MENTE ES UN RECIPIENTE (Llamas 2005: 134). Esta es la metáfora que subyace a expresiones metafóricas del español como no me cabe en la cabeza, no me entra la lección, métete esto en la cabeza, ser un cabeza hue$c a$, etc. Se trata de una comparación bastante frecuente en la anatomía humana 
y animal, pues son diversas las partes del cuerpo que suelen compararse con recipientes. Véanse, entre otros, los compuestos sintagmáticos formados con los sustantivos caja (caja de las muelas 'encías', 'toda la boca'; caja del cuerpo 'tórax'; caja del tambor o del tímpano 'parte media del órgano del oído de la mayoría de los vertebrados', DRAE 2001: s. v. caja) y arca (arca del cuerpo 'tronco del cuerpo' y arca del pan 'vientre', DRAE 2001: s. v. arca).

En nuestro corpus, la mayoría de denominaciones metafóricas se corresponde con una metáfora en la que la cavidad ocular, es decir, el hueco en el que se halla el globo del ojo, se identifica con un recipiente (EL OJO ES UN RECIPIENTE). A partir de esta metáfora, las formas de referirse al párpado se pueden clasificar en dos grupos:

(a) Los nombres en los que interviene una metáfora mediante la que el párpado se concibe como la tapa que cubre y cierra el recipiente ocular (EL PÁRPADO ES UNA TAPA). En este grupo, que incluye un número mayor de variantes, se hallan las denominaciones del esp. cobertera del ojo, cubierta del ojo, tapas del ojo, tela del ojo, tela; del cat. clotxa de $l^{\prime}$ ull', pellofa de s'ull, tanca, tapa, tapes de l'ull, tapetes de l'ull, tapa des párpados; del gall. capel, capela, capelo do ollo, tapa do ollo; y del port. capa, capa da vista, capa do olho, capela, capela do olho, capela da vista, capulho do olho, carapela do olho, carapulinha, cobertora, tampa da vista. Todas estas formas léxicas surgen, por tanto, de la comparación de la función del párpado (cubrir el ojo y protegerlo) con la de distintas realidades - una tapa, una capa, una cubierta, una tela, la cáscara de algunos alimentos (pellofa de s'ull) y animales (clotxa de l'ull) - que sirven para cubrir realidades diversas. Según los datos de Zauner (1903: 377), esta metáfora se da también en designaciones de otras variedades románicas en las que se compara el ojo con una tapa (fr. uviarkl dals ẹl's y coviek di l'oûie) o una capa y un sombrero (fr. chape, chapiau de l'œil). Esta asociación es bastante recurrente en las designaciones y conceptualizaciones anatómicas, pues diversas partes del cuerpo se comparan con tapas que recubren aquello que se concibe como un receptáculo (tapa de los sesos 'parte superior del cráneo', $D R A E$ 2001: s. v. tapa). Así pues, podría afirmarse que el cuerpo se entiende como un recipiente que contiene o está formado, a su vez, de pequeños recipientes y, algunos de ellos, poseen tapas cobertoras. Además, esta metáfora es probable que esté condicionada, como también lo estuvieron las formas latinas PALPĚBRA y PALPĚTRA, -UM (vid. § 3), por

\footnotetext{
${ }^{8}$ Se ha interpretado que el primer sustantivo de esta lexía compleja se corresponde con la voz clotxa 'caparazón' (DCVB s. v., DIEC s. v.), aunque no se descarta que la metáfora a partir de la que se ha formado esta designación haya podido surgir a partir de otras acepciones de la misma voz (p. e. 'hoyo'). En este caso, si fuera así, la metáfora subyacente a la denominación se correspondería con las formas que se han clasificado en el grupo (b) de este epígrafe.
} 
el movimiento de los párpados, ya que estos permiten abrir y cerrar los ojos igual que se abre y cierra cualquier recipiente.

(b) Las designaciones que surgen por un proceso metafórico y otro metonímico. Por un lado, parece que se relaciona metafóricamente el ojo como una cavidad o recipiente y, por otro, que mediante una reducción metonímica se denomina el párpado a partir de la metáfora con la que se concibe todo el globo ocular. En este grupo, se incluyen las formas del esp. casa del ojo; y del cat. guarnició de l'ull y olla de s'ull. Todas constituyen ejemplos de la estrecha relación que mantienen la metáfora y la metonimia — denominada metaphtonymy por Goossens (1995) en los procesos de conceptualización de partes del cuerpo y en su representación lingüística. Desde el punto de vista metafórico, estas denominaciones resultan especialmente interesantes por la diversidad de dominios origen (source domain) que intervienen en ellas: una casa, una olla y una fortificación. En este último caso, para clasificar la designación guarnició de l'ull, se ha partido de una acepción antigua de la voz ('fortificació: obra de defensa per a la guerra') que recoge el $D C V B$ (s. v. guarnició). No obstante, cabe señalar que otras acepciones de esta voz permitirían realizar interpretaciones diversas de la denominación que podrían estar vinculadas a otras designaciones metafóricas (esp. ribetes del ojo).

\subsubsection{Metáforas orientacionales}

Las metáforas orientacionales se caracterizan por organizar un sistema de conceptos en relación a otros y por estar vinculadas a cuestiones de orientación y situación en el espacio (arriba-abajo, dentro-fuera, delante-detrás, profundosuperficial, central-periférico). El único caso del corpus que se puede incluir en este grupo es la denominación del cat. cim de l'ull. En esta forma, el párpado se compara con la parte más alta de una montaña (la cima) quizá por tratarse de la zona que queda por encima del globo ocular. El análisis de esta denominación permite advertir que la conceptualización del ojo, como sucede en otras denominaciones de partes del cuerpo (esp. cielo de la boca 'paladar' y cielo de la lengua 'paladar' respuestas recogidas en el mapa 297 del ALeCMan) se organiza en términos o esquemas de verticalidad (arriba-abajo). Este tipo de denominaciones metafóricas corporales suele surgir para dar nombre a pequeñas partes de un conjunto de miembros que conforman un todo. Véase, por ejemplo, el caso de la boca como un TODO cuya parte superior (el paladar) se compara con el cielo; y el ojo, también constituido por distintos miembros, cuya parte más externa (el párpado) se concibe como la cima del conjunto que lo conforma.

\subsubsection{Metáforas estructurales}

Una metáfora estructural es aquella a partir de la que se concibe un concepto en términos de otro (p. e. UNA DISCUSIÓN ES UNA GUERRA, Lakoff y Johnson 1986[1980]: 40). La única designación del párpado que parece que podría co- 
rresponderse con este tipo de metáfora sería el esp. ribetes del ojo si se entiende ribete como "cinta o cosa análoga con que se guarnece y refuerza la orilla del vestido, calzado, etc.' (DRAE 2001 s. v. ribete). Así pues, el ojo se conceptualizaría como una prenda de vestir en la que el párpado realizaría la función de reforzar.

Parece más que probable que exista relación entre esta denominación y la forma del cat. guarnició de l'ull puesto que, como se ha comentado anteriormente (§ 4.1.1.1.), este modo de referirse al párpado surge de la comparación con una fortificación. Por tanto, en el origen metafórico de ambas denominaciones subyace la idea de reforzar, resguardar y proteger que posee el párpado en relación al ojo.

\subsubsection{Metáforas de imagen}

La designación que se analiza en este apartado (port. barbatana) procede de una metáfora de imagen (Lakoff 1987; Lakoff y Turner 1989; Santos y Espinosa 1996: 45). Según Lakoff (1987: 221), este tipo de metáforas se distinguen de las conceptuales, entre otros aspectos, porque no están convencionalizadas; no se emplean en el razonamiento cotidiano del ser humano; se basan en proyecciones de una imagen sobre otra; no se utilizan para comprender lo abstracto en términos de lo concreto; y no tienen su base en el conocimiento común o la experiencia.

La voz portuguesa barbatana, habitualmente empleada para designar la 'aleta del pez' (Houaiss 2003: s. v. barbatana), parece que podría proceder de una metáfora de imagen que consistiría en la proyección de la imagen esquemática de la aleta de un pez sobre el párpado del ojo humano. La comparación de este dominio origen sobre la parte del cuerpo es probable que parta de la imagen prototípica - ya que existen múltiples tipos de aletas según la especie de pezque los hablantes poseen de la aleta caudal o final de los peces:

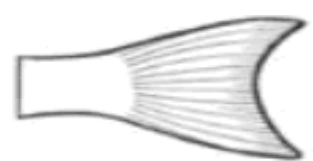

Figura 1. Dominio origen (prototipo de aleta)
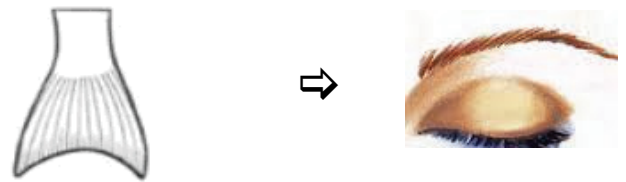

Figura 2. Dominio destino (párpado del ojo cerrado)

La proyección esquemática de la metáfora de imagen parece que se daría en unas condiciones determinadas: la forma que posee el párpado cuando está cerrado se compararía con la imagen del prototipo de aleta caudal de un pez cuando esta está en posición vertical.

\subsection{Variantes léxicas de origen metonímico}

El conjunto de designaciones que se origina mediante un proceso metonímico es menor que el que surge por un mecanismo metafórico. Todas las va- 
riantes metonímicas proceden del tipo de metonimia al que Ullmann (1980[1962]) denominó metonimia espacial y que, en términos cognitivos, se caracteriza porque las transferencias semánticas se producen en el mismo dominio conceptual y porque resultan de la contigüidad física entre los elementos o realidades implicados (Heine 1997: 137-138).

Los intercambios denominativos basados en una metonimia entre nombres de partes del cuerpo contiguas son bastante frecuentes. Véanse, entre otras, las denominaciones románicas de la espalda: lat. SPATǓLA 'omóplato' y 'hombro' > esp. espalda 'espalda'; cat. espatlla 'hombro'; fr. épaule 'hombro'; it. spalla 'hombro'. André (1991:257) califica este cambio léxico-semántico de inconsciente e involuntario y lo relaciona con tres posibles causas: (a) la ignorancia de los hablantes; (b) el conocimiento aproximado de la anatomía que poseen los mismos; y (c) los errores en las localizaciones de las enfermedades o dolores.

Las características del conjunto de denominaciones metonímicas del párpado permiten clasificarlas en dos grupos en función de las partes de la cara con las que se dan las transferencias:

(a) Aquellas que se crean por la contigüidad del párpado con otras partes del ojo: las pestañas (esp. pestañas; cat. pestanyes, palpanyes; gall. pestana, perceba ${ }^{9}$ ), las cejas (cat. celles; port. celha) ${ }^{10}$, la cuenca del ojo (gall. conca, conca do ollo) y la esclerótica (esp. lo blanco del ojo, clara del ojo ${ }^{11}$. Estos casos no son extraños a las lenguas románicas, pues Zauner (1903: 376-377) recoge diversos ejemplos de nombres de otras partes del ojo como denominaciones del párpado: las voces referidas a la ceja son las más frecuentes (rum. suprăceana 'párpado'), también hay casos relativos a las pestañas (rum. geană 'párpado', port. pestanha 'párpado') e, incluso, a la pupila. Entre todas las formas iberorrománicas mencionadas, destaca el cat. palpanyes por su supuesto origen etimológico. Según el $D C V B$ (s. v. palpanya), esta voz procede de un cruce entre las formas palpebra y pestanya y se emplea con el significado de 'pestanya', por ello, se ha clasificado entre las designaciones metonímicas. Según los tipos de etimología popular distinguidos por Veny (1991), el cruce entre las dos voces mencionadas

\footnotetext{
${ }^{9}$ Para más información sobre la etimología y significados de esta voz, véase el $\S 3.1$ y el $\S 3.2$.

${ }^{10}$ En relación a la denominación del párpado mediante los nombres que normalmente se emplean para designar el concepto 'ceja', debe hacerse referencia a las respuestas obtenidas en el ALAnd. Colón (1997: 316) se sorprende de que el mapa del 'párpado' (mapa 1008) de este atlas únicamente contenga la forma celles 'cejas' como respuesta, incluso llega a preguntarse cuál fue la pregunta que se formuló para obtener estos resultados.

${ }^{11}$ Los atlas en los que se incluye un mapa sobre el concepto 'esclerótica' (ALEA mapa 1206, vol. V y ALEANR mapa *949, vol. VII) recogen, entre otras, las formas del esp. lo blanco, lo blanco del ojo y lo claro.
} 
surge, muy probablemente, por un proceso de homonimización semántica, el contenido semántico de uno de los dos parónimos es el que ha provocado la interferencia formal. Asimismo, también cabe una mención especial a la forma clara del ojo recogida en el ALEICan porque podría tratarse de una metáfora de imagen basada en el color blanco de la esclerótica. Así pues, se asociaría esta parte del ojo con un huevo, una comparación que no es ajena a las designaciones de las distintas partes del ojo, véase el cat. iema de l'ull 'pupila' en Julià (2009a).

(b) Aquellas que surgen por la contigüidad del ojo con otras partes de la cara: las mejillas (esp. mejillas del ojo). Esta designación difiere de las anteriores porque la transferencia metonímica se produce con partes del rostro que se sitúan por debajo del ojo.

\section{Análisis de las denominaciones descriptivas}

La descripción de las características principales de las partes del cuerpo es una estrategia designativa frecuente en la lengua común para referirse a las pequeñas partes del cuerpo, tal y como muestran ciertos mapas lingüísticos de este campo conceptual. Buena muestra de ellos son algunos de los nombres de la pupila (bola, boleta, bolica, bola de l'ull y negre de l'ull) recogidos en el $A L D C$ (mapa 18, vol. I) y en el ALEANR (mapa 949, vol. VII) que se investigaron en Julià (2009a); así como también ciertas denominaciones de la nuez (el hueso de la garganta), el esternón (hueso del pecho) o el caño de la nariz (agujero, agujerillo, boquete) que registra el $A L E A^{12}$.

La particularidad principal de este conjunto de designaciones es que, en su mayoría, son lexías complejas que poseen la estructura $[\mathrm{N}+\mathrm{de}+$ artículo $+\mathrm{N}]$ en la que el primer sustantivo significa 'piel' (esp. piel, pellejo; cat. pell; port. pele) o 'masa de carne' (gall. y port. papo) $)^{13}$ y el sintagma preposicional pospuesto a este es de carácter meramente referencial (esp. del ojo, cat. de l'ull, gall. do ollo, port. da vista, do olho).

Las únicas denominaciones que no poseen esta estructura son las voces del catalán (pell) y el portugués (pele) que se corresponden con el primer sustanti-

\footnotetext{
${ }^{12}$ Los mapas del ALEA que se corresponden con estos conceptos son los siguientes: nuez (mapa 1230 , vol. V), esternón (mapa 1248, vol. V) y caño de la nariz (mapa 1209, vol. V).

${ }^{13}$ Papo se emplea, en general, para designar aquellas partes del cuerpo que poseen volumen carnoso (la mejilla, el pulpejo, el abdomen). En el $D R A G$ (s. v. papo), se especifica que «normalmente nesta acepción vai especificada polo nome da parte do corpo á que corresponde. Déronlle unha patada no papo da perna». Por ello, no es extraño que los índices del $A L G a$ $(<$ http://ilg.usc.es/indices/>) recojan, además de la lexía papo do ollo con el significado de 'párpado', la forma papo y otras lexías complejas que contienen esta voz con distintos significados, aunque siempre referidos al cuerpo humano (gall. papo 'pescozo', 'queixo', 'papo da orella', 'faceira', 'papo do dedo', 'coxa'; papo da cara 'faciera'; papo inchado 'bocio'; beber a papo 'beber á catalá').
} 
vo de las formas complejas mencionadas; la lexía compleja del esp. pellejo de la bola del ojo, cuya diferencia principal con las formas más comunes es que el sintagma preposicional pospuesto al sustantivo pellejo contiene otro sintagma preposicional (de la bola del ojo); y el gall. sobreollo, que se diferencia del resto de designaciones por ser un compuesto léxico cuyo carácter descriptivo consiste en denominar el párpado como aquella parte del cuerpo que se encuentra encima del ojo. Sin embargo, a pesar de las diferencias estructurales, todas estas formas de referirse al párpado se caracterizan por compartir el mismo origen motivacional ya que son nombres con los que se describe esta parte del ojo.

\section{Conclusiones}

De la investigación llevada a cabo, se extraen resultados de dos tipos: unos de carácter general sobre las informaciones etimológicas y semánticas que contienen los materiales geolingüísticos y los beneficios de analizarlas aplicando las teorías y postulados de la semántica cognitiva; y otros más concretos sobre la caracterización onomasiológica del concepto 'párpado' en las variedades iberorrománicas.

El análisis de los mapas da cuenta de que, como han demostrado Alinei $(1984,1989,2002)$ y García Mouton $(1990,2010)$ en numerosas ocasiones, los mapas lingüísticos constituyen fuentes de consulta imprescindibles para cualquier estudio lexicológico sobre la motivación del signo y la historia de las palabras. Por un lado, los mapas del párpado muestran que una de las principales motivaciones en la zona iberorrománica para referirse al párpado está vinculada a la conceptualización de la cavidad ocular como recipiente, un esquema metafórico ontológico universal. Por otro lado, la distribución y el uso de las formas derivadas del lat. PALPĚBRA (esp. párpado, cat. parpella; gall. y port. palpebra; gall. perceba) aporta referencias a la historia que puede trazarse de estas voces a partir de los textos antiguos y diccionarios históricos o etimológicos.

Los datos geolingüísticos han permitido comprobar, como en otras investigaciones (Navarro Carrasco 1988; Fuster Berenguer 1996-1997; Juilà 2007, 2009a, 2009b, 2010), que las estrategias designativas en el lenguaje popular son mayoritariamente metafóricas. Igualmente, se advierte que la metonimia y la descripción son dos recursos que también se emplean en la creación denominativa de partes del cuerpo. Se constata, además, que el estudio del léxico de los atlas desde la perspectiva de la semántica cognitiva permite aproximarse a la estructura subyacente de la creación del lenguaje natural, esto es, a los procedimientos mediante los que se conceptualiza el mundo y la manera en la que estos se expresan lingüísticamente.

El pormenorizado análisis de las distintas formas de referirse al párpado en las variedades románicas de la Península Ibérica muestra que se trata de un concepto que presenta un importante grado de variación denominativa (más de 
60 formas). Este elevado número de variantes léxicas no es ajeno al estudio onomasiológico de los nombres de las partes del cuerpo ya que es equivalente a los resultados obtenidos en otros casos investigados. Muestra de ello son las 50 formas de referirse a la 'pupila' que se examinaron en Julià (2009a) o los más de 40 nombres del 'dedo pulgar' que se han estudiado en Julià (2010). La comparación de los resultados obtenidos en las investigaciones mencionadas ha permitido suponer que una de las razones de esta amplia variedad designativa en los conceptos 'párpado', 'pupila' y 'dedo pulgar' —y los del resto de partes del ojo y dedos de la mano investigados en Julià (2007) y (2010) respectivamentepodría deberse a que se trata de pequeñas partes del cuerpo poco prototípicas que forman parte de un todo mayor (el ojo y la mano). Como consecuencia de su falta de prototipicidad, parece que estos conceptos suelen ser concebidos y entendidos mediante otras realidades (dominio meta) a diferencia de lo que les sucede a aquellas partes del cuerpo más prototípicas (mano, ojo, dedo) que normalmente presentan un reducido grado de variación léxica y sirven de fuente de conceptualización cognitiva (dominio origen).

Asimismo, aunque las formas procedentes del latín PALPËBRA y PALPĚTRA, -UM, populares o cultas, son las más usuales para designar el párpado, como sucede también para otras partes del cuerpo (p. e. DIGITUS INDEX $>$ dedo índice y DIGITUS ĀNULĀRIS > dedo anular), el resto de formas léxicas son creaciones que proceden principalmente de una metáfora o una metonimia.

De los dos mecanismos, la metáfora es indiscutiblemente el más productivo. El examen de las formas léxicas ha permitido comprobar que de los distintos tipos de metáforas que distinguen Lakoff y Johnson (1986[1980]), la metáfora conceptual ontológica de recipiente, que consiste en la comparación de la cavidad ocular con un recipiente y del párpado con la tapa del mismo, es la que genera más denominaciones (esp. cobertera del ojo, cat. pellofa de s'ull, gall. capelo do ollo, port. capa da vista). Asimismo se recogen, aunque son pocos los testimonios, ejemplos creados mediante metáforas orientacionales (cat. cim de l'ull) y estructurales (esp. ribetes del ojo); así como también algún caso vinculado a una metáfora de imagen (port. barbatana) procedente de una curiosa proyección esquemática (la imagen de la aleta caudal de un pez se proyecta sobre la imagen del párpado).

La investigación semántica de las designaciones permite advertir que las características físicas del párpado son los factores mayoritarios que motivan las designaciones de esta parte del cuerpo. Por un lado, el movimiento repetitivo de esta parte del cuerpo es el motivo que da lugar al lat. PALPĚBRA, un origen que actualmente no es transparente para los hablantes y que tampoco parece haber generado, según el material de los atlas, denominaciones románicas. Este aspecto merece ser destacado porque para otras partes del cuerpo se ha podido comprobar que es habitual la conservación del motivo latino en formas de creación románica. Es el caso, por ejemplo, de la pupila, cuya metáfora latina 
(la comparación de la imagen reflejada en la pupila con una figura de apariencia humana) se ha mantenido en las variedades románicas de los atlas (p. e. esp. señorita, niña del ojo; cat. ànima de l'ull; gall. criatura, santo). Por otro lado, siguiendo la línea de las investigaciones sobre la universalidad de la conceptualización de los nombres de las partes del cuerpo (Tagliavini 1949; Brown y Witkowsky 1981), se advierte la existencia de estrategias comunes en las variedades iberorrománicas (p. e. metáfora de recipiente: EL OJO ES UN RECIPIENTE y EL PÁRPADO ES LA TAPA DEL RECIPIENTE) que motivan, a su vez, designaciones sinónimas formal, estructural y significativamente (esp. tapas del ojo, cat. tapes de l'ull, gall. tapa do ollo, port. tampa da vista).

En esencia, la investigación semántico-etimológica de los nombres del párpado recogidos en los atlas lingüísticos pone de manifiesto que los mapas geolingüísticos constituyen corpus de datos léxico-semánticos que contienen informaciones de especial interés en las investigaciones cognitivas panrománicas en las que se investigan las relaciones de conceptualización de la realidad. Además de recoger información sobre la variación diatópica y designativa de un concepto, tras las respuestas cartografiadas se hallan datos cognitivos subyacentes de carácter relevante que permiten advertir la existencia de patrones de conceptualización y creación léxica comunes a las variedades románicas estudiadas. Estos resultados, en contraste con los que se han obtenido en otros trabajos que también parten de los materiales de los atlas lingüísticos, permiten dar cuenta de la importancia de la metáfora por encima de cualquier otro mecanismo cognitivo en la percepción de una realidad tan cotidiana como es el cuerpo humano. Asimismo, se advierte que el estudio de este dominio semántico es idóneo para el análisis del modo en el que la mente humana percibe la realidad a partir de la evidencia lingüística y que la lingüística cognitiva aporta las herramientas de análisis adecuadas para explotar al máximo los datos de los atlas lingüísticos y contribuir así, a la caracterización del lenguaje natural.

\section{Referencias bibliográficas}

(a) Atlas lingüísticos

[AIS] JABERG, Karl y Jakob JUD (1928-1940): Sprach-und Sachatlas Italiens und der Südschweiz. Zofingen: Gedruck mit Unterstützung der Gesellschaft für Wissenschaftliche Forschung an der Universität Zurich und privater Freunde des Werkes von der Verlagsanstalt Ringier \& Co.

[ALAnd] GRIERA, Antoni (1973): Atles Lingüístic d'Andorra. Barcelona: Polígrafa. 
[ALCyL] ALVAR, Manuel (1999): Atlas lingüistico de Castilla y León. Salamanca: Junta de Castilla y León-Consejería de Educación y Cultura, 3 vols.

[ALDC] VeNY Clar, Joan y Lídia PONS GRIERA (2001-): Atles lingüistic del domini català. Barcelona: Institut d'Estudis Catalans.

[ALEA] ALVAR, Manuel (1963-1973): Atlas lingüistico y etnográfico de Andalucía. Granada: Universidad de Granada, 6 vols.

[ALEANR] ALVAR, Manuel (1979-1983): Atlas lingüistico y etnográfico de Aragón, Navarra y Rioja (con la colaboración de Antonio Llorente, Tomás Buesa y Elena Alvar). Madrid: La Muralla, 12 vols.

[ALEICan] ALVAR, Manuel (1975-1978): Atlas lingüistico y etnográfico de las Islas Canarias. Madrid: La Muralla, 3 vols.

[ALECant] Alvar, Manuel (1995): Atlas lingüistico y etnográfico de Cantabria. Madrid: Arco/Libros, 2 vols.

[ALeCMan] GARCÍA MOUTON, Pilar y Francisco MORENO FERNÁNDEZ (1987-): Atlas lingüistico y etnográfico de Castilla La Mancha. [En línea, $<$ http://www.uah.es/otrosweb/ alecman/>].

[ALEPG] SARAMAGO, João (dir.) (en prensa): Atlas Linguístico-Etnográfico da Portugal e da Galiza. Lisboa: Centro de Linguística da Universidade de Lisboa.

[ALF] GILLIÉRON, Jules y Edmond EDMONT (1902-1910): Atlas Linguistique de la France. Paris: Honoré Champion, 12 vols.

[ALGa] García GonzÁlez, Constantino y Antón Santamarina Delgado (1990-): Atlas lingüístico galego. Santiago de Compostela: Universidade de Santiago-Instituto da Lingua Galega, 6 vols.

(b) Referencias bibliográficas

AlineI, Mario (1984): Dal totemismo al cristianesimo popolare. Sviluppi nei dialetti italiani ed europei. Torino: Edizioni dell'Orso.

(1989): "Geografia semantica: continuatori di draco in Italia e in Francia", in Études de dialectologie et de géolinguistique offerts à Gaston Tuaillon, vol. II, pp. 459-487. Grenoble: Ellug/Université Stendhal Grenoble 3.

(1997): "L'aspect magico-religieux dans la zoonymie populaire", in Les zoonymes. Actes du colloque international tenu à Nice les 23, 24, 25 janvier 1997, Sylvie Mellet (ed.), pp. 9-22. Nice: Centre de recherches comparatives sur les langues de la Méditerranée ancienne.

(2002): "Il ruolo della motivazione nel lessico", in Dialectoloxía e Léxico, Rosario Álvarez Blanco, Francisco Dubert García y Xulio Sousa Fernández (eds.), pp. 15-28. Santiago de Compostela: Consello da Cultura Galega/Instituto da Lingua Galega.

(2005): "Names of Animals, Animals as Names: Synthesis of a Research», in Animal Names, Alessandro Minelli, Gherardo Ortalli, Glauco Sanga (eds.), pp. 245-268. Venezia: Istituto Veneto di Scienze, Lettere ed Arti. 
Alvar, Manuel (1982): “Atlas lingüísticos y diccionarios”. Lingüistica Española Actual IV/2: 253-323.

Álvarez PÉrez, Xosé A. (2009): "Herramientas informáticas para el estudio diacrónico del gallego", in Tendencias actuales en la investigación diacrónica de la lengua, Laura Romero Aguilera y Carolina Julià Luna (coords.), pp. 117-124. Barcelona: Publicacions i Edicions de la Universitat de Barcelona.

ANDRÉ, Jacques (1978): Les mots a redoublement en latin. Paris: Éditions Klincksieck.

(1991): Le vocabulaire latin de l'anatomie. Paris: Les Belles Lettres.

BuenAfUENTES DE LA MATA, Cristina (2007): Procesos de gramaticalización y lexicalización en la formación de compuestos en español, 2 vols. Bellaterra: Universitat Autònoma de Barcelona. [Tesis doctoral digitalizada en $<\mathrm{http}: / /$ www.tesisenxarxa.net/TDX-0321107-17284> ]. (2010): La composición sintagmática en español. San Millán de la Cogolla: Cilengua.

BROWN, Cecil H. y Stanley R. WITKOWSKI (1981): "Figurative Language in a Universalist Perspective". American Ethnologist 8/3: 596-615.

Bustos GISBERT, Eugenio de (1986): La composición nominal en español. Salamanca: Ediciones Universidad de Salamanca.

CAPRINI, Rita y Rosa RONZITTI (2007): "Studio iconomastico dei nomi della 'pupilla' nelle lingue indoeuropee e nei dialetti romanzi". Quaderni di Semantica XXVIII/2: 287-326.

CARPITELLI, Elisabetta (2006): "Il nome della trottola in Alta Val di Magra: fra onomasiologia e semasiologia". Quaderni di Semantica XVII/1-2: 167-181.

CASTAÑER MARTín, Rosa M. ${ }^{a}$ (2009): "El atlas lingüístico como fuente lexicográfica. Del ALEANR al DDEAR". Archivo de Filología Aragonesa 65: 139164.

CifUENTES HonRUBIA, José Luis (1992): "Teoría de prototipos y funcionalidad semántica". Estudios de Lingüistica. Universidad de Alicante (E.L.U.A.) 8: 133-177.

ClAVERÍA NADAL, Gloria (en prensa): "Nuevas perspectivas en el estudio de la evolución del léxico", in Historia del léxico: perspectivas de investigación, Gloria Clavería Nadal, Margarita Freixas Alás, Marta Prat Sabater y Joan Torruella Casañas (eds.). Madrid/Frankfurt: Iberoamericana/Vervuert.

COLÓN DOMÉNECH, Germà (1997): "Entorn l'atles lingüístic d'Andorra", in Estudis de filologia catalana i romànica, pp. 305-327. València-Barcelona: Institut Universitari de Filologia Valenciana-Publicacions de l'Abadia de Montserrat.

CONTINI, Michel (2005): «Formazione fonosimboliche negli zoonimi dell'area romanza. Reflessioni sulle carte dell'ALiR», in Els mètodes en dialectologia: continuïtat o alternativa. I Jornada de l'Associació d'amics del professor Antoni M. Badia i Margarit (Barcelona, 11 de març de 2004), pp. 6790. Barcelona: Institut d'Estudis Catalans. 
COSERIU, Eugenio (1977): "La geografía lingüística", in El hombre y su lenguaje. Estudios de teoría y metodología lingüistica, pp. 103-158. Madrid: Gredos.

CUENCA ORDIÑANA, M. ${ }^{a}$ Josep y Joseph HILFERTY (1999): Introducción a la lingüística cognitiva. Barcelona: Ariel.

DALBERA, Jean-Philippe (2006): Des dialectes au langage. Une archéologie du sens. Paris: Honoré Champion.

[DCVB] AlCOVER I SUREDA, Antoni M. a y Francesc De B. Moll i CASANOVAS (2002[1962]): Diccionari català-valencià-balear. Barcelona: Institut d'Estudis Catalans.

[DECat] Corominas VigneauX, Joan (1980-1991): Diccionari etimologic $i$ complementari de la llengua catalana (con la colaboración de Joseph Gulsoy y Max Cahner). Barcelona: Curial.

[DEILE] ROBERTS, Edward A. y Bárbara PASTOR (1996): Diccionario etimológico indoeuropeo de la lengua española. Madrid: Alianza.

[DELL] ERNOUT, Alfred y Antoine MEILLET (1967[1932]): Dictionnaire étymologique de la langue latine. Histoire des mots. Paris: Klincksieck.

[DHLF] REY, Alain (dir.) (1992): Dictionnaire historique de la langue française. Paris: Dictionnaires Le Robert.

DÍAZ ROJO, José Antonio (2002): "El fonosimbolismo: ¿propiedad natural o convención cultural?". Revista electrónica de estudios filológicos 3. [En línea, <http://www.um.es/ tonosdigital/znum3/estudios/fonosimbDiazRojo. htm\#_ftn7>].

[DIEC] INSTITUT D'ESTUDIS CATALANS (2007): Diccionari de la llengua catalana, 2. ${ }^{\text {a }}$ edición. Barcelona: Edicions 62-Enciclopèdia Catalana. [En línea $<$ http://dlc.iec.cat/ $>$ ].

[DRAG] Real ACademia Galega (1997): Diccionario da Real Academia Galega. A Coruña: Real Academia Galega. [En línea $<$ http://www.edu.xunta.es/diccionarios/index rag.html >].

DWORKIN, Steven N. (2006a): "La naturaleza del cambio léxico", in Actas del VI Congreso Internacional de Historia de la Lengua Española. Madrid (29 de septiembre a 3 de octubre de 2003), José J. de Bustos Tovar y José L. Girón Alconchel (eds.), vol. I, pp. 67-84. Madrid: Arco/Libros. (2006b): "Recent Developments in Spanish (and Romance) Historical Semantics", in Selected Proceedings of the 8th Hispanic Linguistics Symposium, Timothy L. Face y Carol A. Klee (eds.), pp. 50-57. Somerville, MA: Cascadilla Proceedings Project.

Fuster Berenguer, M. ${ }^{\text {a }}$ Trinidad (1996-1997): "Voces de creación metafórica sobre el maíz y el trigo en el Atlas Lingüístico de Aragón, Navarra y La Rioja". Estudios de Lingüistica 11: 139-148.

GARCíA Mouton, Pilar (1990): "El estudio léxico en los mapas lingüísticos", in Estudios sobre variación lingüística, Francisco Moreno Fernández (recop.), pp. 27-75. Salamanca: Universidad de Alcalá de Henares. 
(1996): "Dialectología y geografía lingüística", in Manual de dialectología hispánica. El español de España, Manuel Alvar (dir.), pp. 63-77. Barcelona: Ariel.

(2007): "Las disciplinas tradicionales (II). Dialectología y geolingüística", in Manual de lingüistica románica, José Enrique Gargallo Gil y María Reina Bastardas (coords.), pp. 319-350. Barcelona: Ariel.

(2010): "Si el DRAE utilizase los atlas lingüísticos...: un ejemplo aragonés", in De moneda nunca usada. Estudios filológicos dedicados a José M. ${ }^{a}$ Enguita Utrilla, Rosa M. ${ }^{a}$ Castañer Martín y Vicente Lagüéns Gracia (eds.), pp. 271-282. Zaragoza: Inst. "Fernando el Católico".

GOOSSENS, Louis (1995): "Metaphtonymy: the Interaction of Metaphor and Metonymy in Figurative Expressions for Linguistic Action", in By Word of Mouth. Metaphor, Metonymy and Linguistic Action in a Cognitive Perspective, Louis Goossens et al. (eds.), pp. 159-174. Amsterdam-Philadelphia: John Benjamins.

GONZÁLEZ GONZÁLEZ, Manuel (1992): "Metodología de los atlas lingüísticos en España", in Nazioarteko Dialektologia Bilzarra. Agiriak. (IKER 7), pp. 151-177. Bilbao: Real Academia de la lengua vasca.

GORDÓN PERAL, M. a Dolores y Stefan RUHSTALLER KuHNE (2008): “Atlas lingüísticos y toponimia como fuentes en el estudio histórico del léxico", in Actas del VII Congreso Internacional de Historia de la Lengua Española: Mérida (Yucatán) 4-8 de septiembre de 2006, Concepción Company Company y José G. Moreno de Alba (coords.), vol. II, pp. 1347-1358. Madrid: Arco/Libros.

GosCHLER, Juliana (2005): "Embodiment and Body Metaphors". Metaphorik.de 09: 33-52.

HEINE, Bernd (1997): Cognitive Foundations of Grammar. Oxford: Oxford University Press.

[Houaiss] HOUAISS, Antônio; Mauro DE SALLES VILlaR y Francisco Manoel DE MELlo FrANCO (eds.) (2003): Diccionario Houaiss da língua portuguesa. Lisboa: Temas e Debates.

INTITUTO DA LingUa GALEGA [en línea]: Índices do Atlas lingüístico galego, $<$ http://ilg.usc.es/indices/>. [Consulta: 04/11/2010]

IORDAN, Iorgu (1967): Lingüística románica. Evolución-corrientes-métodos. Madrid: Ediciones Alcalá [Reelaboración y notas de Manuel Alvar].

JABERG, Karl (1959[1908]): Geografía lingüística. Ensayo de interpretación del «Atlas Lingüístico de Francia». Granada: Universidad de Granada. [Traducción por Antonio Llorente y Manuel Alvar de Sprachgeographie. Beitrag zum Verstädnis des "Atlas Linguistique de la France». Aurau: Druck und Verlag von H. R. Sauerländer \& Co.]

JOHNSON, Mark (1992[1987]): El cuerpo en la mente: fundamentos corporales del significado, la imaginación y la razón. Madrid: Debate [Traducción de The Body in the Mind: The Bodily Basis of Meaning, Imagination and Reason. Chicago: The University of Chicago Press]. 
Julià LunA, Carolina (2007): Léxico y variación: las denominaciones de las partes del ojo. Bellaterra: Universitat Autònoma de Barcelona. [Trabajo de investigación disponible en línea $<\mathrm{http} / /$ www.recercat.net/handle/ 2072/4360>].

(2009a): "Los nombres de la pupila en los atlas regionales de la Península Ibérica". Lingüistica Española Actual 31/1: 89-131.

- (2009b): "El cuerpo humano en la creación y motivación de los nombres románicos de insectos". Revue de Linguistique Romane tomo 73, n. ${ }^{\circ}$ 291292: 321-369.

(2010): Estructura y variación en el léxico del cuerpo humano. Bellaterra: Univeristat Autònoma de Barcelona. [Tesis doctoral dirigida por la Dra. Gloria Clavería Nadal disponible en línea $<$ http://www.tesisenxarxa.net/ TDX-1222110-163719/>].

KLEIBER, Georges (1995): La semántica de los prototipos: categoría y sentido léxico. Madrid: Visor.

LABOV, William (1974): "The Boundaries of Words and their Meanings", in New Ways of Analyzing Variation in English, Charles J. Baley y Roger W. Shuy (coords.), pp. 340-373. Washington: Georgetown University Press.

LAKOFF, George (1987): "Image Metaphors". Metaphor and Symbolic Activity 2/3: 219-222.

LAKOFF, George, y Mark JOHNSON (1986[1980]): Metáforas de la vida cotidiana. Madrid: Cátedra [Traducción de Metaphors We Live By. Chicago: The University of Chicago Press].

LAKOFF, George, y Mark TURNER (1989): More than Cool Reason: A Field Guide to Poetic Metaphor. Chicago: University of Chicago Press.

Llamas SAíz, Carmen (2005): Metáfora y creación léxica. Pamplona: Ediciones Universidad de Navarra, S. A.

Malkiel, Yakov (1990): Diachronic Problems on Phonosymbolism. Amsterdam: John Benjamins.

(1994): "Regular Sound Development Phonosymbolic Orchestration, Disambiguation of Homonyms", in Sound Symbolism, John J. Ohala, Leanne Hinton y Johanna Nichols (eds.), pp. 207-221. Cambridge: Cambridge University Press.

MÁRQUEZ LINARES, Carlos Francisco (1998): La polisemia en el campo léxico "el cuerpo humano": un estudio contrastivo inglés-español, Córdoba: Universidad de Córdoba [Tesis doctoral inédita].

MARTíN-MUNICIO, Ángel (1992): "La metáfora en el lenguaje científico". Boletín de la Real Academia Española LXXII, cuaderno CCLVI: 221-249.

MARTINS-BALTAR, Michel y Geneviève CALBRIS (1997): Le corps dans la langue. Esquisse d'un dictionnaire onomasiologique. Notions et expressions dans le champ de «dent» et de «manger». Tübingen: Max Niemeyer. (2009): "Sémiologie de l'acte 'manger': Source et objet de figures". Semiotica 93/3-4: 207-240. 
Mateu Fontanals, Jaume (2009): "Modelos cognitivos", in Panorama de la lexicología, Elena de Miguel (ed.), pp. 281-300. Barcelona: Ariel.

NAVARRO CARRASCO, Ana Isabel (1988): "Voces de creación metafórica en el ALEA". Lingüistica Española Actual X: 107-114.

- (2001): "Yayo en los diccionarios y en los atlas lingüísticos". Revista de Filología Española LXXXI/1-2: 185-193.

NEBRIJA, Antonio de (1973[1516]): Vocabulario de romance en latín. Madrid: Castalia [Introducción de Gerald J. Macdonald].

NeGro Romero, Marta (2008): "O léxico tradicional no campo semántico das partes da cabeza: proposta de recuperación nos diccionarios normativos". Estudos de Lingüistica Galega 1: 235-246.

OlZA MORENO, Inés (2007): “¿Cómo conceptualizan el lenguaje los hablantes del español? El caso de los somatismos basados en boca", in Interculturalidad y lenguaje I. El significado como corolario cultural, Juan de Dios Luque Durán y Antonio Pamies Bertrán (eds.), pp. 235-251. Granada: Método. (2009): "Habla, soy todo oídos. Reflexo das accións e das actitudes do receptor na fraseoloxía somática metalingüística do español". Cadernos de fraseoloxía galega 11: 139-162.

PEÑA CERVEL, Sandra (2001): "A Cognitive Approach to the Role of Body Parts in the Conceptualization of Emotion Metaphors". EPOS XVII: 245260.

POCH OLIVÉ, Dolors (2010): "Los poemas no existen más que en la voz", in $A l$ otro lado del espejo. Comentario lingüístico de textos literarios. Estudios en homenaje a José Manuel Blecua Perdices, Gloria Clavería Nadal y Dolors Poch Olivé (coords.), pp. 187-216. Barcelona: Ariel.

PRAT SABATER, Marta (2006): "Reflejo espacial del cambio léxico: los atlas lingüísticos y el DCECH', in Actes del VII Congrés de Lingüistica General (Barcelona, 18-21 abril 2006), pp. 1-15. Barcelona: Universitat de Barcelona. [Edición en CD-ROM].

[REW] MEYER-LÜBKE, Wilhelm (1968[1911]): Romanisches Etymologisches Wörterbuch, 4. ${ }^{\mathrm{a}}$ edición. Heidelberg: Winter.

RosCH, Eleanor (1978): "Principles of Categorization", in Cognition and Categorization, Eleanor Rosch y Barbara B. Lloyd (eds.), pp. 27-48. Hillsdale (N.J.): Lawrence Erlbaum Associates.

SANTOS Domínguez, Luis A. y Rosa M. ${ }^{\text {a }}$ EsPinosa Elorza (1996): Manual de semántica histórica. Madrid: Síntesis.

SARAMAGO, João (2006): "O Atlas Lingüístico-Etnográfico de Portugal e da Galiza (ALEPG)". Estudis romànics XXVIII: 281-298.

SweETSER, Eve E. (1990): From Etymology to Pragmatics. Metaphorical and Cultural Aspects of Semantic Structure. Cambridge: Cambridge University Press.

TAGLIAVINI, Carlo (1949): "Di alcuni denominazioni della < pupila > (studio di onomasiologia, con speciale riguardo alle lingue camito-semitiche e negro 
africane)". Annali dell'Istituto Universitario Orientale di Napoli III: 341378.

[TILG] SANTAMARINA FERNÁNDEZ, Antón (ed.) (2003): Tesouro informatizado da lingua galega. Santiago de Compostela: Instituto da Lingua Galega [en línea], <http://ilg.usc.es/tmilg> [Consulta: 31/10/2010].

UlLmanN, Stephen (1980[1962]): Semántica. Introducción a la ciencia del significado. Madrid: Aguilar. [Traducción de Semantics: an Introduction to the Science of Meaning. Oxford: Basil Blackwell].

VAL ÁlvARO, José F. (1999): "La composición”, in Gramática descriptiva de la lengua española, Ignacio Bosque Muñoz y Violeta Demonte Barreto (eds.), vol. III, pp. 4757-4841. Madrid: Espasa-Calpe.

VENY CLAR, Joan (1991): "Cap a una tipologia de l'etimologia popular", in Mots d'ahir i mots d'avui, pp. 69-95. Barcelona: Empúries. - (2000): "De la nineta a l'ànima de l'ull", in Jornades de la secció filologica de l'Institut d'Estudis Catalans a Elx $i$ a la Universitat d'Alacant (16 i 17 d'octubre de 1998), pp. 83-92. Barcelona-Elx: Institut d'Estudis CatalansAjuntament d'Elx,

ZAUNER, Adolf (1903): "Die romanischen Namen der Körperteile". Romanische Forschungen XIV: 339-530. 